\title{
Diversity of plants used for nest-building by Cheiracanthium japonicum (Araneae: Miturgidae)
}

\author{
Yutaka Hironaka ${ }^{1} \&$ Hiroshi Abé \\ Graduate School of Environment and Information Sciences, Yokohama National University, \\ 79-7 Tokiwadai, Hodogaya-ku, Yokohama, Kanagawa, 240-8501 Japan \\ Email: hironaka-yutaka-px@ynu.ac.jp \\ ${ }^{2}$ Biological laboratory, College of Bioresource Sciences, Nihon University, 1866 Kameino, Fujisawa, \\ Kanagawa, 252-0880 Japan
}

\begin{abstract}
The taxonomic diversity and biological features of plant species used for nest-building by the Japanese foliage spider Cheiracanthium japonicum were examined. The spider builds three types of nests in its life cycle, namely, for molting, mating, and breeding, using a plant leaf. In total, 23 plant species of 21 genera in seven families were recorded as plants used by C. japonicum. Twenty species among the 23 species were recorded for the first time. Most of these plants were classified in the families Poaceae and Asteraceae. The number of plant species was the highest for the molting nest and the lowest for the breeding nest. As nest types changed from molting to breeding, the number of plant species used for nest-building decreased sharply, and adult female spiders used poaceous plants almost exclusively to build a breeding nest because their leaves are larger and longer than those of the other plant taxa. Of the three types of nests, the breeding nest was barrel-shaped, and the poaceous species was considered to be the most suitable for C. japonicum to build a barrel-shaped breeding nest.
\end{abstract}

Key words - silken nest, plant usage by spiders, nesting behavior

Some spiders use plant leaves as a habitation substratum. A crab spider, Misumena vatia, selects leaves of the common milkweed (Asclepias syriaca) for nest-building, and the reproductive success of the spider depends on the plant species used for its nest (Morse 1990). Leaf selection for habitation is considered to be crucial for the adaptation of a spider. In fact, some hunting spiders exhibit precise selection of plant leaves for their habitations (Romero \& Vasconcellos-Neto 2005a, b). However, studies on the biological features of plant species used for spider habitation are quite limited.

The Japanese foliage spider, Cheiracanthium japonicum Bösenberg \& Strand 1906, is a wandering spider inhabiting grasslands throughout Japan (Ono 2009). It is known that the spider builds a nest constructed primarily of a monocotyledonous plant leaf bound with spider silk for molting, mating, and breeding during its life cycle (Nakahira 1966). The form of nests varies according to the spider's developmental stages and its usages, i.e., molting, mating, and breeding (Fig. 1). A juvenile builds a molting nest for molting into the next stage (Nakahira 1966). During the reproductive period, copulation occurs in the nest just after the sub-adult female molts into the adult (Nakahira 1966). If a male finds an adult female in the mating nest, copulation occurs there at once (Hironaka personal observation). The adult female builds a breeding nest for egg-laying (Nakahira
1966). Every type of nest is constructed primarily of a plant leaf bound with spider silk (Nakahira 1966). We observed that plant species used for the nests varied according to the nest type. As the spider's developmental stages proceed, the spider is expected to require a larger space in the nest. Therefore, the biological features of plant species used for the nests possibly vary with the nest type. To date, only three plant species, Eragrostis ferruginea, Miscanthus

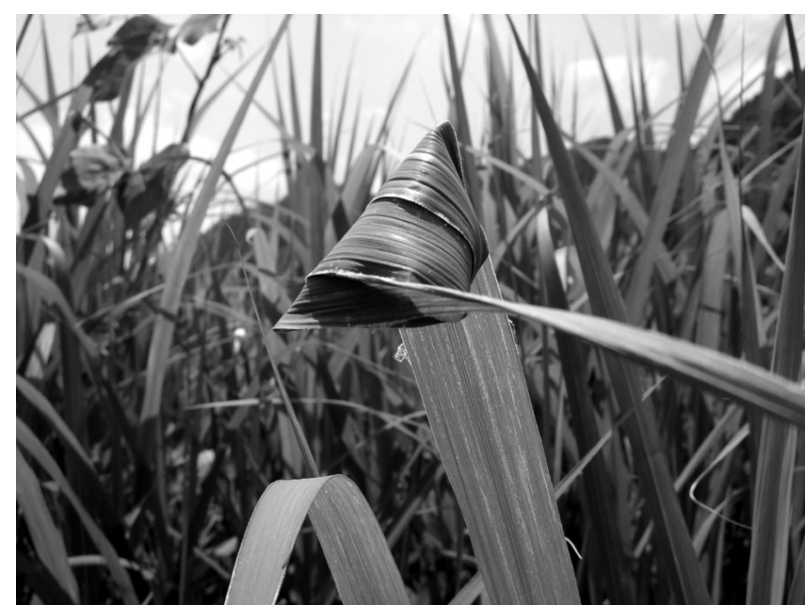

Fig. 1. A breeding nest built with a leaf of Miscanthus sacchariflorus by a female of Cheiracanthium japonicum. 
sinensis, and Phragmites australis, are known to be used by C. japonicum (Nakahira 1966, Ori 1976, Toyama 1999, Ono 2009). Moreover, these three plants were recorded as a result of studies on breeding nests exclusively. There are no reports on plant species used by $C$. japonicum to build other types of nests or on the biological features of the plants. Consequently, to understand the nesting ecology of $C$. japonicum, we revealed the taxonomic diversity and biological features of plant species used for nest-building by $C$. japonicum through its life cycle.

Twenty-five investigations were conducted from April in 2007 to October in 2009 at five study areas. The areas were located in Kanagawa Prefecture, Japan: $35^{\circ} 22^{\prime} 23^{\prime \prime} \mathrm{N}, 139^{\circ}$ $22^{\prime} 22^{\prime \prime} \mathrm{E}$; $35^{\circ} 31^{\prime} 29^{\prime \prime} \mathrm{N}, 139^{\circ} 13^{\prime} 20^{\prime \prime} \mathrm{E} ; 35^{\circ} 34^{\prime} 03^{\prime \prime} \mathrm{N}, 139^{\circ} 19^{\prime} 07$ "E; $35^{\circ} 34^{\prime} 23^{\prime \prime} \mathrm{N}, 139^{\circ} 18^{\prime} 22^{\prime \prime} \mathrm{E} ; 35^{\circ} 34^{\prime} 37^{\prime \prime} \mathrm{N}, 139^{\circ} 18^{\prime} 22^{\prime \prime} \mathrm{E}$. These areas were grass-covered plains mainly dominated by Miscanthus sacchariflorus, M. sinensis, Phragmites australis, and P. japonica in Poaceae and Solidago altissima in Asteraceae. The investigations were carried out during the daytime because the spider uses a nest for resting and hiding during the daytime, although the spider is nocturnal. We searched for the nests of $C$. japonicum by haphazardly walking around the grassland, and we recorded the plant species used for the spiders' nests. The nests can be categorized into the following three types based on the stage of the spider:

1) Molting: built by juveniles for molting.

2) Mating: built by a single sub-adult female for final molting and pre-mating, by a single adult for pre-mating, or by an adult pair or an adult male and a sub-adult female pair for mating.

3) Breeding: built by an adult female for breeding.

To reveal the morphological traits of plant species used for the spiders' nests, we examined the length, width, and surface area (leaf length $\times$ leaf width) of the plant leaf used for each nest according to Satake et al. (1981, 1982, and 1989), Osada (1989), and Shimizu (2003). The measured values were compared among the nest types by using the Kruskal-Wallis tests to examine the relationship between the morphological traits of plant species and nest types. In addition, to detect the morphological traits of plant species used for each nest type, the measured values of plant species used for each nest type were compared with those not used for each nest type by using the Wilcoxon rank-sum tests.

We examined 287 molting, 55 mating, and 101 breeding nests during the survey. The plant species used for the spider nests are shown in Table 1. In total, 23 species of 21 genera in seven families were recorded as plants used for nest-building by $C$. japonicum. Twenty of 23 species were newly recorded as plants used by the spider in the present study. C. japonicum used Miscanthus sacchariflorus, $M$. sinensis, and Phragmites japonica in Poaceae and Solidago altissima in Asteraceae to build three types of nests. These four plant species reported above were multipurpose plants used by the spider. On the other hand, the juveniles of $C$. japonicum used the following 13 plant species exclusively to build a molting nest: Cleistogenes hackelii, Digitaria ciliaris, Elymus racemifer, Eragrostis ferruginea, Lolium

Table 1. Plants $(*)$ used for molting, mating, and breeding nests of Cheiracanthium japonicum. Leaf dimensions are from Satake et al. (1981, 1982, and 1989), Osada (1989), and Shimizu (2003). In the case of compound leaves, only the terminal leaflet was measured.

\begin{tabular}{|c|c|c|c|c|c|c|c|c|}
\hline \multicolumn{3}{|c|}{ Plant taxon } & \multicolumn{3}{|c|}{ Nest type } & \multicolumn{3}{|c|}{ Leaf measurement (average) } \\
\hline Order & Family & Species & Molting & Mating & Breeding & $\begin{array}{c}\text { Length } \\
(\mathrm{mm})\end{array}$ & $\begin{array}{l}\text { Width } \\
(\mathrm{mm})\end{array}$ & $\begin{array}{c}\text { Length } \times \\
\text { Width }\left(\mathrm{cm}^{2}\right)\end{array}$ \\
\hline \multirow{12}{*}{ Poales } & Poaceae & Cleistogenes hackelii & $*$ & & & 70.0 & 5.0 & 3.5 \\
\hline & & Digitaria ciliaris & $*$ & & & 90.0 & 6.5 & 5.9 \\
\hline & & Elymus racemifer & $*$ & & & 175.0 & 6.0 & 10.5 \\
\hline & & Eragrostis ferruginea & $*$ & & & 300.0 & 4.5 & 13.5 \\
\hline & & Imperata cylindrica & $*$ & & $*$ & 350.0 & 9.5 & 33.3 \\
\hline & & Lolium multiflorum & $*$ & & & 155.0 & 5.5 & 8.5 \\
\hline & & Miscanthus sacchariflorus & $*$ & $*$ & $*$ & 500.0 & 20.0 & 100.0 \\
\hline & & M. sinensis & $*$ & $*$ & $*$ & 400.0 & 13.0 & 52.0 \\
\hline & & Paspalum dilatatum & $*$ & & & 200.0 & 7.5 & 15.0 \\
\hline & & Phragmites australis & & & $*$ & 350.0 & 30.0 & 105.0 \\
\hline & & P. japonica & $*$ & $*$ & $*$ & 200.0 & 25.0 & 50.0 \\
\hline & & Setaria glauca & $*$ & & & 175.0 & 5.5 & 9.6 \\
\hline Myrtales & Onagraceae & Oenothera biennis & $*$ & $*$ & & 135.0 & 32.5 & 43.9 \\
\hline Fabales & Fabaceae & Pueraria lobata & $*$ & & & 125.0 & 125.0 & 156.3 \\
\hline Rosales & Rosaceae & Rosa multiflora & $*$ & $*$ & & 30.0 & 30.0 & 9.0 \\
\hline Gentianales & Rubiaceae & Paederia scandens & $*$ & & & 70.0 & 40.0 & 28.0 \\
\hline \multirow[t]{6}{*}{ Asterales } & Asteraceae & Artemisia princeps & $*$ & $*$ & & 90.0 & 60.0 & 54.0 \\
\hline & & Bidens frondosa & $*$ & & & 80.0 & 15.0 & 12.0 \\
\hline & & Conyza sumatrensis & $*$ & & & 115.0 & 15.0 & 17.3 \\
\hline & & Picris hieracioides & $*$ & & & 90.0 & 15.0 & 13.5 \\
\hline & & Solidago altissima & $*$ & $*$ & $*$ & 95.0 & 15.0 & 14.3 \\
\hline & & Stenactis annuиs & $*$ & & & 100.0 & 22.5 & 22.5 \\
\hline Caryophyllales & Polygonaceae & Fallopia japonica & $*$ & $*$ & & 105.0 & 70.0 & 73.5 \\
\hline Total & & 23 & 22 & 8 & 6 & & & \\
\hline
\end{tabular}


multiflorum, Paspalum dilatatum, and Setaria glauca in Poaceae, Pueraria lobata in Fabaceae, Paederia scandens in Rubiaceae, and Bidens frondosa, Conyza sumatrensis, Picris hieracioides, and Stenactis annuus in Asteraceae. Adult females of the spider used Phragmites australis in Poaceae only for building a breeding nest. Through the life cycle of $C$. japonicum, the spider most frequently used the plant species in Asteraceae and Poaceae for nest-building. These two plant families were uniquely used for a breeding nest by adult females. According to field observations in the study areas, the spiders seemed to choose a specific plant species for nest-building regardless of its abundance in their habitat.

The median values of the leaf measurements of plant species used for each nest type and those not used for each nest type are shown in Table 2. There were no significant differences in the length, width, and surface area of the plant leaf used for the nest among nest types (Kruskal-Wallis test: leaf length, $\chi^{2}=4.58, P=0.10$; leaf width, $\chi^{2}=3.13, P=0.21$; leaf surface area, $\left.\chi^{2}=4.84, P=0.09\right)$. On the other hand, there was a significant difference in leaf width (Wilcoxon rank-sum test, $W=94.0, P=0.03$ ) and a weak difference in leaf surface area (Wilcoxon rank-sum test, $W=89.0, P$ $=0.07$ ) between plant species used for a mating nest and those not used for a mating nest. In addition, there were significant differences in leaf length (Wilcoxon rank-sum test, $W=90.5, P=0.01$ ) and leaf surface area (Wilcoxon ranksum test, $W=82.0, P=0.03$ ) between plant species used for a breeding nest and those not used for a breeding nest. These results indicated that the ranges of leaf measurement values overlap among the nest types but the morphological traits of plant species used for mating and breeding nests were more specific; in other words, the plant leaf used for the mating nest was wider, and that used for the breeding nest was larger and longer.

The number of plant species was the highest for a molting nest and the lowest for a breeding nest. This tendency suggests that it is not necessary for the juvenile of $C$. japonicum to select any specific plant species for building a molting nest because its only requirement is to build a nest that will accommodate its small body size for hiding and molting in a temporary location. On the other hand, the spider tends to choose a specific plant species with large and significantly wide leaves for building a mating nest. It is highly likely that the adult spider requires larger space in proportion to its larger body size than the juvenile in a mating nest. Except for one breeding nest that was built with asteraceous leaves, the remaining 100 breeding nests were constructed with poaceous leaves. Therefore, the adult female has a noticeable tendency to use a particular plant species that is limited almost exclusively to the family Poaceae in order to build a breeding nest, the final nest in the spider's life cycle. In addition, the leaves of these plant species were larger and longer than those of the other plant species. The spider prefers the poaceous species because its plants generally have larger and longer leaves than those of
Table 2. Median values of leaf measurements used and those not used for each nest type.

\begin{tabular}{lcccc}
\hline Nest type & $n$ & $\begin{array}{c}\text { length } \\
(\mathrm{mm})\end{array}$ & $\begin{array}{c}\text { width } \\
(\mathrm{mm})\end{array}$ & $\begin{array}{c}\text { surface } \\
\text { area }\left(\mathrm{cm}^{2}\right)\end{array}$ \\
\hline Molting & 22 & 120 & 15.0 & 16.1 \\
No molting & 1 & 350 & 30.0 & 105 \\
Mating & 8 & 120 & 27.5 & 51.0 \\
No mating & 15 & 125 & 9.50 & 13.5 \\
Breeding & 6 & 350 & 17.5 & 51.0 \\
No breeding & 17 & 105 & 15.0 & 13.5 \\
\hline
\end{tabular}

the other plant taxa examined in this study. The nest size correlates with the fecundity of the Cheiracanthium species (Kikuchi \& Ohkawara 2007). The inner space is formed in relation to the overall shape of the nest. Without exception, all breeding nests were barrel-shaped (Nakahira 1966, Hironaka personal observation). In contrast to the shape of other types of nests, the barrel seems to provide a larger inner space for successful oviposition and newborn juveniles. Leaves of the poaceous species are considered to have the most suitable form for C. japonicum to build a barrel-shaped breeding nest.

\section{References}

Kikuchi, T. \& Ohkawara, K. 2007. Factors affecting offspring number of Japanese foliage spider, Cheiracanthium lascivum (Araneae: Clubionidae). Acta Arachnol., 56: 91-95. (In Japanese with English summary)

Morse, D. H. 1990. Leaf choices of nest-building crab spiders (Misumena vatia). Behav. Ecol. Sociobiol., 27: 265-267.

Nakahira, K. 1966. Reproductive behaviors of Chiracanthium japonicum Bösenberg et Strand (Araneae, Clubionidae). Atypus, 41/42: 15-23. (In Japanese)

Ono, H. 2009. Chiracanthiidae. pp. 464-466. In: Ono, H. (ed.) The spiders of Japan with keys to the families and genera and illustrations of the species. Tokai Univ. Press, Kanagawa, 738 pp. (In Japanese)

Ori, M. 1976. Studies on the poisonous spider Chiracanthium japonicum Bösenberg et Stand, 1906, as a pest of medical importance. 2. Ecological studies on the spider, Chiracanthium japonicum, Bösenberg et Stand, 1906. Jap. J. Sanit. Zool., 27: 181188. (In Japanese with English summary)

Osada, T. 1989. Illustrated grasses of Japan. Heibonsha, Tokyo, 759 pp. (In Japanese)

Romero, G. Q. \& Vasconcellos-Neto, J. 2005a. Spatial distribution and microhabitat preference of Psecas chapoda (Peckham \& Peckham) (Araneae, Salticidae). J. Arachnol. 33: 124-134.

Romero, G. Q. \& Vasconcellos-Neto, J. 2005b. The effects of plant structure on the spatial and microspatial distribution of a bromeliadliving jumping spider (Salticidae). J. Anim. Ecol. 74: 12-21.

Satake, Y., Ohwi, J., Kitamura, S., Watari, T. \& Tominari, T. (eds.) 1981. Wild flowers of Japan III: herbaceous plants (including Dwarf Subshrubs). Heibonsha, Tokyo, 259 pp. (In Japanese)

Satake, Y., Ohwi, J., Kitamura, S., Watari, T. \& Tominari, T. (eds.) 1982. Wild flowers of Japan II: herbaceous plants (including Dwarf Subshrubs). Heibonsha, Tokyo, 318 pp. (In Japanese)

Satake, Y., Hara, H., Watari, S. \& Tominari, T. (eds.) 1989. Wild flowers of Japan I: woody plants. Heibonsha, Tokyo, 321 pp. (In Japanese)

Shimizu, T. (ed.) 2003. Naturalized plants of Japan. Heibonsha, Tokyo, 337 pp. (In Japanese)

Toyama, M. 1999. Adaptive advantages of maternal care and matriphagy in a foliage spider, Chiracanthium japonicum (Araneae: Clubionidae). J. Ethol., 17: 33-39.

Received November 7, 2011 / Accepted September 26, 2012 